\title{
Lumbar fusion did not differ from cognitive therapy plus exercise for reducing disability and pain in chronic low back pain
}

Brox Jl, Sørensen R, Friis A, et al. Randomized clinical trial of lumbar instrumented fusion and cognitive intervention and exercises in patients with chronic low back pain and disc degeneration. Spine 2003;28:1913-1921.

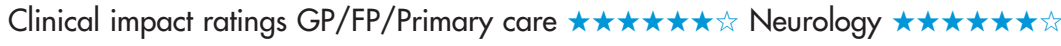

In patients with chronic low back pain (CLBP), is instrumented lumbar fusion (ILF) more effective than cognitive therapy plus exercise (CTE) for reducing CLBP related disability and pain?

METHODS

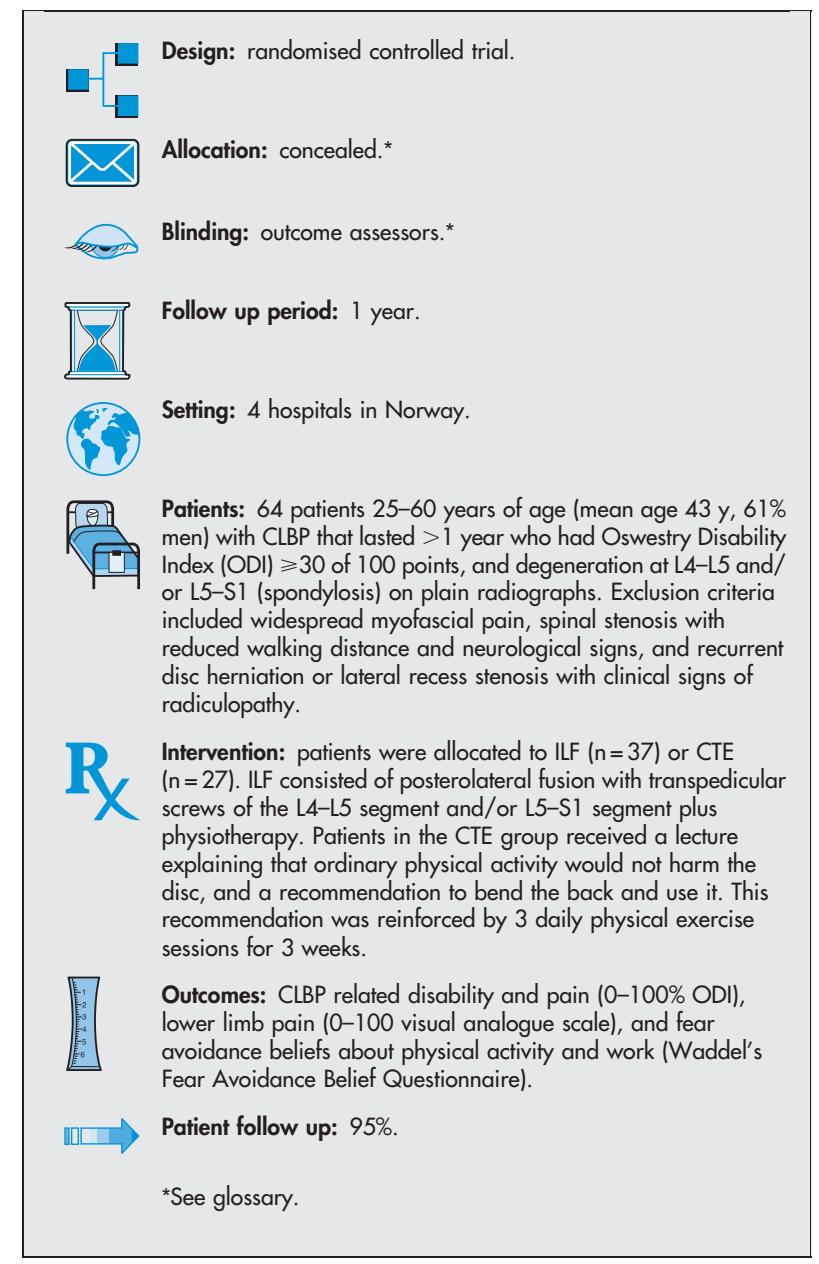

MAIN RESULTS

Analysis was by intention to treat. The groups did not differ for change from baseline in CLBP related disability and pain (table). Reduction from baseline in lower limb pain was greater in the ILF group than in the CTE group (table). Reduction in fear avoidance beliefs was greater in the CTE group than in the ILF group (table).

\section{CONCLUSIONS}

In patients with chronic low back pain (CLBP), instrumented lumbar fusion (ILF) did not differ from cognitive therapy plus exercise for reducing CLBP related disability and pain. However, ILF improved lower limb pain.

For correspondence: Dr j I Brox, National Hospital, Oslo, Norway. jens.ivar.brox@rikshospitalet.no

Sources of funding: Norwegian Federal Government and Health and Rehabilitation Foundation.

\section{Commentary}

he study by Brox et al tackles the most difficult and frustrating group of patients with CLBP - those who have had pain for longer than a year. A previous randomised controlled trial by the Swedish Lumbar Spine Study Group compared lumbar fusion with usual care in this group of patients and found lumbar fusion to be better. ${ }^{1}$ They also found that personality factors and low disc height predicted improvement after surgical treatment. ${ }^{2}$ The study by Brox et al compares fusion with an intensive non-surgical approach using fear avoidance therapy. Other researchers have shown that this form of physical therapy reduces disability in patients with elevated fear avoidance beliefs in the face of acute LBP, ${ }^{3}$ but until now, it has not been studied in CLBP. Exercise has been shown to be more effective than usual care for $\mathrm{CLBP}^{4}$ as has intensive multidisciplinary biopsychosocial rehabilitation with a functional restoration approach. ${ }^{5}$

The study by Brox et al is one of the few rigorous studies that have compared active treatments for CLBP. However, the level of intensity used in this study may not be achievable in physician practice settings. Based on this assumption, primary care physicians could consider the use of fear avoidance therapy and exercise for patients with assistance from physiotherapists, clinical psychologists, or other qualified personnel.

Katherine Margo, MD

University of Pennsylvania

Philadelphia, Pennsylvania, USA

1 Fritzell P, Hagg O, Wessberg P, et al. 2001 Volvo Award Winner in Clinical Studies: Lumbar fusion versus nonsurgical treatment for chronic low back pain: a multicenter randomized controlled trial from the Swedish Lumbar Spine Study Group. Spine 2001;26:2521-32; discussion 2532-4.

2 Hagg O, Fritzell P, Ekselius L, et al. Predictors of outcome in fusion surgery for chronic low back pain. A report from the Swedish Lumbar Spine Study. Eur Spine J 2003;12:22-33.

3 George SZ, Fritz JM, Bialosky JE, et al. The effect of a fear-avoidance-based physical therapy intervention for patients with acute low back pain: results of a randomized clinical trial. Spine 2003;28:2551-60.

4 van Tulder MW, Malmivaara A, Esmail R, et al. Exercise therapy for low back pain. Cochrane Database Syst Rev 2000;(2):CD000335.

5 Guzman J, Esmail R, Karjalainen K, et al. Multidisciplinary bio-psychosocial rehabilitation for chronic low back pain. Cochrane Database Syst Rev 2002;(1):CD000963.

Instrumented lumbar fusion (ILF) $v$ cognitive therapy plus exercise (CTE) in chronic low back pain at 1 year*

\begin{tabular}{|c|c|c|c|}
\hline \multirow[b]{2}{*}{ Outcomes } & \multicolumn{2}{|c|}{$\begin{array}{l}\text { Mean } \\
\text { change } \\
\text { from } \\
\text { baseline }\end{array}$} & \multirow{2}{*}{$\begin{array}{l}\text { Difference between } \\
\text { groups }(95 \% \mathrm{Cl})\end{array}$} \\
\hline & ILF & CTE & \\
\hline $\begin{array}{l}\text { Disability and pain (0-100 } \\
\text { Oswestry Disability Index) }\end{array}$ & 15.6 & 13.3 & $2.3(-6.8$ to 11.4$)$ \\
\hline $\begin{array}{l}\text { Lower limb pain (0-100 } \\
\text { visual analogue scale) }\end{array}$ & 16.9 & -1.5 & $18.4(4.3$ to 30.7$) \dagger$ \\
\hline $\begin{array}{l}\text { Fear avoidance beliefs about } \\
\text { physical activity (FABQ-PA) }\end{array}$ & 2.2 & 9.9 & $-7.7(-11.6$ to -3.8$) \ddagger$ \\
\hline $\begin{array}{l}\text { Fear avoidance beliefs } \\
\text { about work (FABQ-W) }\end{array}$ & -1.1 & 5.6 & $-6.7(-13.7$ to -3.0$) \pm$ \\
\hline
\end{tabular}

*FABQ-PA $=0-24$ Waddel's Fear Avoidance Belief Questionnaire about physical activity; FABQ-W = 0-36 Waddel's Fear Avoidance Belief Questionnaire about work. $\mathrm{Cl}$ defined in glossary. †Significant difference favours ILF.

‡Significant difference favours CTE. 